\title{
Nutritional Status Assessment of Minodar Residence in Qazvin City, Iran: Vitamin D Deficiency in Sunshine Country, a Public Health Issue
}

\author{
Amir Ziaee ${ }^{1}$, Amir Javadi ${ }^{2}$, Maryam Javadi ${ }^{3}$, Mohammadali Zohal ${ }^{4} \&$ Ahmad Afaghi $^{5}$ \\ ${ }^{1}$ Qazvin Metabolic Diseases Research Center, Qazvin University of Medical Sciences, Qazvin, Iran \\ ${ }^{2}$ Community Medicine, School of Medicine, Qazvin University of Medical Sciences, Qazvin, Iran \\ ${ }^{3}$ Department of Nutrition, School of Health, Qazvin University of Medical Sciences, Qazvin, Iran \\ ${ }^{4}$ Department of Internal Medicine, School of Medicine, Qazvin University of Medical Sciences, Qazvin, Iran \\ ${ }^{5}$ Qazvin Research Center for Social Determinants of Health Science (QRC SDH), Qazvin University of Medical \\ Sciences, Qazvin, Iran \\ Correspondence: Mohammadali Zohal, Qazvin University of Medical Sciences, Qazvin, Iran. E-mail: \\ zohal11@yahoo.com
}

Received: September 29, 2012 Accepted: November 9, 2012 Online Published: November 21, 2012

doi:10.5539/gjhs.v5n1p174 URL: http://dx.doi.org/10.5539/gjhs.v5n1p174

Conflict of interest: There was no conflict of interest

\begin{abstract}
Introduction: Nutrition has main effect on health or disease and results of nutrition assessment can be used in health planning of communities. Therefore we aimed to conduct the nutrition assessment especially vitamin D statue of an urban region in Qazvin city.

Methods: In a cross sectional study in year 2011, subjects who were randomly selected from residents of aged $\geq$ 20 years old in Minodar, an urban region of Qazvin city participated in this study. A 3-days food diary questionnaire was used to collect food consumption data and weight and height of subjects were measured. The food intake was analysis using "Nutrition 4, Diet analysis, Module version 3.5.2".

Results: The participants included 930 subjects ( $434 \mathrm{M}$ and $496 \mathrm{~F}$ ) having Mean BMI $=26 \pm 4.4 \mathrm{~kg} / \mathrm{m}^{2}$ and $60 \%$ of subjects were either overweight or obese. Daily energy intake of $50 \%$ of subjects was more than $2500(13.6 \%$ from proteins, $55.6 \%$ from carbohydrate and $30.5 \%$ from fat sources). The daily cholesterol intake among $50-75 \%$ of population was more than daily recommended of $300 \mathrm{mg}$. The mean iron and zinc intakes were $17 \pm 5.6$ and $12 \pm 4.5 \mathrm{mg}$ /day and the intakes were highest in aged group of 20-29, while reduced in older groups. Vitamin A deficiency was observed in studied population and $75 \%$ of them were receiving less than daily recommended allowance of $800 \mu \mathrm{g} / \mathrm{day}, 25 \%$ of total studied population was receiving less than $400 \mu \mathrm{g} / \mathrm{day}$. Vitamin D ingestion among $90-95 \%$ of participants was less than minimum daily recommended amount of 10 $\mu \mathrm{g} /$ day and calcium intake in $50-75 \%$ of studied population was less than recommended daily allowance of 800 $\mathrm{mlg}$ /day. High amount of florid and caffeine ingestion from black tea was observed among population and $75 \%$ of population had florid intake of $10000 \mathrm{~m} \mu$ /day.
\end{abstract}

Conclusion: In general, majority of the population of region had higher amount intake of fat, cholesterol, low intake of calcium and vitamin D

Keywords: nutrition assessment, energy, mineral, vitamin D

\section{Introduction}

Nutrition has main effect on health or disease and results of nutrition assessment can be used in health planning of communities. Micronutrients deficiencies such as vitamin $\mathrm{A}, \mathrm{D}, \mathrm{Ca}^{2+}$ and Iron have been demonstrated in different countries including Iran. In previous study (ERC Accessed Sep.2012) in Tehran population it was demonstrated that $30 \%$ of energy intake was from fat sources and cholesterol intake was higher than RDA recommendation of $300 \mathrm{mg}$. The $\mathrm{Ca}^{2+}$ and Iron intake were lower than RDA recommendation (Mahan and Escott-Stump, 2012). 
Among micronutrient the vitamin D deficiency is now recognized as a pandemic. The major cause of vitamin D deficiency is the lack of moderate sunlight exposure. Limited animal sources of foods are rich in vitamin D, and foods that are fortified with vitamin D are often are not enough to provide population needs. Vitamin D deficiency causes rickets in children and leads to osteopenia, osteoporosis, and consequently bone fractures in adults. Vitamin D deficiency has been associated with increased risk of common cancers, autoimmune diseases, hypertension, and infectious diseases (Holick and Chen 2008). The relation between vitamin D deficiency and heart disease has been demonstrated in different studies (Sun et al., 2011)

In China, the prevalence of vitamin D deficiency investigated using serum 25(OH)D among 6008 children of 1 month to 16 years old in Hangzhou (latitude: $30^{\circ} \mathrm{N}$ ). In winter and spring, more than $50 \%$ of school age children and adolescents had a $25(\mathrm{OH}) \mathrm{D}$ level at $<50 \mathrm{nmol} / \mathrm{L}$. If the threshold is changed to $<75 \mathrm{nmol} / \mathrm{L}$, all of the adolescents (100\%) and $93.7 \%$ of school age children had low 25(OH)D levels in winter (Zhu et al., 2012). In randomly assigned $540 \mathrm{urban} /$ rural centers in Turkey Approximately $60 \%$ of the population had severe/moderate Vitamin-D deficiency (Satman et al., 2012). According to different studies that have been conducted across India, there are widespread prevalence of varying degrees (50- 90\%) of Vitamin D deficiency with low dietary calcium intake in Indian population (Londhey, 2011) and in Iran the moderate to sever vitamin D deficiency was reported between 37.5-54.5\% among adults in multi-center studies (Heshmat et al., 2008). Also, the prevalence of moderate to mild vitamin D deficiency in a cross sectional study in year 2010 among 420 (220 girls, 200 boys) secondary school students in Arak city (Iran) was 22.4 and 60.7\% respectively (Talaei et al., 2012).

In study conducted by Moradzadeh et al. (2008), the prevalence of vitamin D deficiency among adults of 20-29 years old in 5 regions of Iran with different climate has been reported as $75 \%$ and $74 \%$ in women and men respectively. In another study carried out by Heshmat et al. (2008) in a random cluster sample of 5232 men and women in 5 major cities of Iran in year 2001 (Tehran, Tabriz, Mshhad, shiraz, Boshehr), the prevalence of vitamin $\mathrm{D}$ deficiency in men and women were $44.2-47.2 \%$ and $37.5 \%-54.2 \%$ respectively. The highest prevalence was observed in Tehran while the lowest was observed in south of Iran, Bosher which was assumed to be due to heterogeneity in Bosher region. Also Hashemipour et al. (2004) reported that, the sever, moderate and mild vitamin D deficiency in Tehranian population was $9.5 \%, 57.6 \%$ and $14.2 \%$ respectively. Different studies in Iran (Hashemipour et al., 2004; Rahnavard et al., 2010) did not observe any relation between blood serum vitamin D level and time exposure to sunlight, however they found the geographic area as independent factor for blood serum vitamin D level (Rahnavard et al., 2010).

Anecdotal studies demonstrated that there are wide spread blood serum vitamin D concentration deficiency in Qazvin region. Therefore we aimed to conduct the nutrition assessment of an urban region in Qazvin city to find out the macro and micro nutrient intake specifically Vitamin D ingestion.

\section{Methods}

In a cross sectional study, randomly selected subjects from residents of aged $\geq 20$ years old in Minodar, an urban region of Qazvin city (Iran) participated in this study. A 3-days Food diary questionnaire was used to collect food consumption data and weight and height of subjects were measured. Subjects who were consuming supplement excluded from the study. The food intake were analyzed using "Nutrition 4, version 3.5.2" software (Nutrition 4, 2011). The research proposal was approved by Ethical Committee of Qazvin University of Medical Sciences.

\section{Results}

The participants included 930 subjects (434 M and $496 \mathrm{~F}$ ) with their age groups in Table 1 . The study population had mean BMI $=26 \pm 4.4 \mathrm{~kg} / \mathrm{m}^{2}$ and $60 \%$ of subjects were either overweight or obese. Daily energy intake of $50 \%$ of subjects was more than $2500 \mathrm{kcal}$ ( $13.6 \%$ proteins, $55.6 \%$ carbohydrate and $30.5 \%$ from fat sources) having 20 gr. daily fiber (Table 2). The daily cholesterol intake among $50-75 \%$ of population was more than daily recommended of $300 \mathrm{mg}$. (Table 2). The mean iron and zinc intakes were $17 \pm 5.6$ and $12 \pm 4.5 \mathrm{mg} /$ day respectively and the intakes were highest in aged group of 20-29, while reduced in older groups (Table 3). Vitamin A intake deficiency was observed in studied population and $75 \%$ of them were receiving less than daily recommended allowance of $800 \mu \mathrm{g} /$ day, and $25 \%$ of total studied population was receiving less than $400 \mu \mathrm{g} / \mathrm{day}$ vitamin A (Table 4). Vitamin D ingestion among $90-95 \%$ of participants was less than the minimum daily recommended amount of $10 \mu \mathrm{g}$ /day (Table 4) and calcium intake in $50-75 \%$ of studied population was less than recommended daily allowance of $800 \mathrm{mg} /$ day (Table 3). High amount of florid and caffeine ingestion from black tea was observed among population and $75 \%$ of population had florid intake of more than $10000 \mu \mathrm{g} / \mathrm{day}$. 
Table 1. Age group of studied population

\begin{tabular}{lll}
\hline Age group & No & Percent \\
\hline $20-29$ & 164 & 17.6 \\
$30-39$ & 225 & 24.2 \\
$40-49$ & 399 & 42.9 \\
$50-59$ & 104 & 11.2 \\
$60-69$ & 27 & 2.9 \\
$>=70$ & 11 & 1.2 \\
Total & 930 & 100 \\
\hline
\end{tabular}

Table 2. Energy, macronutrient and fiber intake in studied population

\begin{tabular}{|c|c|c|c|c|c|c|c|c|c|c|c|}
\hline & & $\begin{array}{l}\text { Energy } \\
\text { Kcal }\end{array}$ & $\begin{array}{l}\mathrm{CHO} \\
\mathrm{gr}\end{array}$ & $\begin{array}{l}\text { Cholesterol } \\
\mathrm{mg}\end{array}$ & $\begin{array}{l}\text { Protein } \\
\text { gr }\end{array}$ & $\begin{array}{l}\text { Fat } \\
\text { gr }\end{array}$ & $\begin{array}{l}\text { Fiber } \\
\text { gr }\end{array}$ & Protein $\%$ & $\mathrm{CHO} \%$ & Fat $\%$ & $\begin{array}{l}\mathrm{BMI} \\
\mathrm{Kg} / \mathrm{m}^{2}\end{array}$ \\
\hline & No & 929 & 930 & 930 & 930 & 930 & 930 & 930 & 930 & 926 & 930 \\
\hline Mean & & 2591 & 364 & 306 & 89 & 89 & 20 & 13.6 & 55.6 & 30.5 & 26 \\
\hline SD & & 703 & 113 & 172 & 28 & 32 & 7 & 2.2 & 7.1 & 7 & 4.4 \\
\hline Minimum & & 1046 & 109 & 43 & 27 & 16 & 5 & 2 & 17 & 10 & 14.8 \\
\hline Maximum & & 5591 & 957 & 1299 & 338 & 359 & 87 & 30 & 76 & 58 & 46 \\
\hline \multirow{7}{*}{ percentile } & 5 & 4416 & 215 & 109 & 55 & 45 & 10 & 44 & 19 & 18.7 & 11.3 \\
\hline & 10 & 1797 & 238 & 132 & 60 & 53 & 11 & 47 & 21 & 20.3 & 12.8 \\
\hline & 25 & 2098 & 286 & 183.6 & 70 & 67.3 & 12 & 51 & 26 & 23 & 15.5 \\
\hline & 50 & 2505 & 347 & 270.9 & 85 & 85 & 13 & 56 & 31 & 25.8 & 19.3 \\
\hline & 75 & 2951 & 422 & 390 & 101 & 105.8 & 15 & 60 & 35 & 28.7 & 24.2 \\
\hline & 90 & 3480 & 503 & 506.9 & 121 & 129 & 16 & 64.9 & 39 & 31.5 & 29.9 \\
\hline & 95 & 3861 & 577 & 621.4 & 139 & 149.8 & 18 & 67 & 42 & 33.7 & 32.6 \\
\hline
\end{tabular}

Table 3. Caffeine and mineral intake in studied population

\begin{tabular}{|c|c|c|c|c|c|c|c|c|c|}
\hline & $\begin{array}{l}\mathrm{Ca} \\
\mathrm{mg}\end{array}$ & $\begin{array}{l}\mathrm{Zn} \\
\mathrm{mg}\end{array}$ & $\begin{array}{l}\mathrm{P} \\
\mathrm{mg}\end{array}$ & $\begin{array}{l}\mathrm{Cu} \\
\mathrm{mg}\end{array}$ & $\begin{array}{l}\mathrm{Mn} \\
\mathrm{mg}\end{array}$ & $\begin{array}{l}\text { Florid } \\
\mu \mathrm{g}\end{array}$ & $\begin{array}{l}\text { Caffeine } \\
\mathrm{mg}\end{array}$ & $\begin{array}{l}\mathrm{Fe} \\
\mathrm{mg}\end{array}$ & $\begin{array}{l}\mathrm{Mg} \\
\mathrm{mg}\end{array}$ \\
\hline No & 930 & 930 & 930 & 930 & 930 & 930 & 929 & 930 & 930 \\
\hline Mean & 733 & 12.5 & 12.5 & 1.7 & 6.6 & 18725.6 & 124.9 & 17 & 378 \\
\hline SD & 272 & 4.5 & 4.5 & ---- & 2.2 & 12193.3 & 88.9 & 5.6 & 138.8 \\
\hline Minimum & 133 & 3.3 & 3.3 & 34 & 1.8 & 2 & 0 & 5.6 & 120.5 \\
\hline Maximum & 2114 & 7.5 & 70.5 & 10 & 16.5 & 72257 & 876.6 & 63.5 & 1316 \\
\hline percentile 5 & 378.5 & 7.5 & 88 & 7.5 & 3.6 & 3280 & 25 & 10.4 & 210.9 \\
\hline 10 & 433.5 & 8.6 & 1 & 8.6 & 4.1 & 5457 & 40 & 11.3 & 238.5 \\
\hline 25 & 545.9 & 9.9 & 1.2 & 9.9 & 5.1 & 9731 & 6.6 & 13 & 284.9 \\
\hline 50 & 690.8 & 11.7 & 1.5 & 11.7 & 6.2 & 16121 & 106.6 & 16 & 350.3 \\
\hline 75 & 876.6 & 14 & 1.96 & 14 & 7.8 & 25330 & 166.6 & 19.5 & 440.3 \\
\hline 90 & 1089.9 & 17 & 2.6 & 17 & 9.5 & 34829 & 225 & 23.9 & 558.2 \\
\hline 95 & 1252 & 19 & 3.1 & 19.6 & 10.6 & 42100 & 266.6 & 27.7 & 651 \\
\hline
\end{tabular}


Table 4. Vitamins intake in studied population

\begin{tabular}{|c|c|c|c|c|c|c|c|c|c|}
\hline & & $\begin{array}{l}\mathrm{B} 6 \\
\mu \mathrm{g}\end{array}$ & $\begin{array}{l}\text { B12 } \\
\mu \mathrm{g}\end{array}$ & $\begin{array}{l}\text { Vitamin D } \\
\mu \mathrm{g}\end{array}$ & $\begin{array}{l}\text { Vitamin A } \\
\mu \mathrm{g}\end{array}$ & $\begin{array}{l}\text { Beta carotene } \\
\mu \mathrm{g}\end{array}$ & $\begin{array}{l}\text { Folic acid } \\
\mu \mathrm{g}\end{array}$ & $\begin{array}{l}\text { Vitamin C } \\
\mathrm{mg}\end{array}$ & $\begin{array}{l}\text { Vitamin } \mathrm{E} \\
\mathrm{mg}\end{array}$ \\
\hline \multicolumn{2}{|l|}{$\overline{\text { No }}$} & 930 & 930 & 924 & 914 & 930 & 930 & 928 & 930 \\
\hline \multicolumn{2}{|l|}{ Mean } & 2 & 3.9 & 4.2 & 858.6 & 1591.1 & 514.9 & 146.9 & 24.1 \\
\hline \multicolumn{2}{|l|}{$\mathrm{SD}$} & ----- & 5.8 & 11.6 & 796.4 & 1430.8 & 213.9 & 98.9 & 14.9 \\
\hline \multicolumn{2}{|l|}{ Minimum } & 62 & 43 & 3 & 102.6 & 0 & 35 & 1.6 & 31 \\
\hline \multirow{8}{*}{$\begin{array}{l}\text { Maximum } \\
\text { percentile }\end{array}$} & & 7.3 & 78.9 & 72.4 & 4997.3 & 10501 & 2283 & 570.3 & 112.2 \\
\hline & 5 & 1.1 & 1.6 & ------- & 223.2 & 15.9 & 257.6 & 24.7 & 7.5 \\
\hline & 10 & 1.3 & 1.9 & ------ & 291.1 & 45.3 & 292.9 & 39.3 & 9.9 \\
\hline & 25 & 1.6 & 2.3 & ------ & 401.2 & 535.2 & 372.5 & 71.6 & 14.6 \\
\hline & 50 & 2 & 3 & -------- & 638.6 & 1231.9 & 483.2 & 126.8 & 20.3 \\
\hline & 75 & 2.4 & 3.8 & 1.4 & 958 & 2323.8 & 611.6 & 200.1 & 29.7 \\
\hline & 90 & 2.1 & 4.9 & 4.3 & 1607.3 & 3527.9 & 753.1 & 284.8 & 42 \\
\hline & 95 & 3.5 & 6.6 & 31.3 & 2622.8 & 4377.1 & 900.7 & 345.1 & 55.9 \\
\hline
\end{tabular}

\section{Discussion}

This study demonstrated that, daily energy intake of $50 \%$ of the studied population was more than $2500 \mathrm{kcal}$ having $30.5 \%$ of energy from fat sources (Table 2). The daily cholesterol intake among $50-75 \%$ of population was more than daily recommended of $300 \mathrm{mg}$ (Table 2). The mean iron and zinc intakes were $17 \pm 5.6$ and $12 \pm 4.5$ $\mathrm{mg} /$ day and the intakes were highest in aged group of 20-29, while reduced in older groups (Table 3). Vitamin A intake deficiency was observed in studied population and $75 \%$ of them were receiving less than daily recommended allowance of $800 \mu \mathrm{g} /$ day (Table 4). The $\mathrm{Ca}^{2+}$ intake in $50-75 \%$ of studied population was less than recommended daily allowance of $800 \mathrm{mlg} /$ day and vitamin D ingestion among $90-95 \%$ of participants was less than minimum daily recommended allowance of $10 \mu \mathrm{g} /$ day (Table 4).

Although there are not sufficient micronutrients intakes among studied population, but vitamin D deficiency and its intakes is noticeable point. Vitamin D is an essential factor for normal metabolism of bone, bone minerals and non-bone related metabolic process. Serum vitamin D deficiency in Iran in 5 cities with different climates has been reported in $75 \%$ of women and $72.1 \%$ of men which was similar to the results of other studies in Middle East (Moradzadeh et al., 2008). In a study carried out by Hashemipour et al. (2004) in Tehran (capital of Iran), the vitamin D serum level did not have significant relation with the duration of exposure of face and hands to sunlight, kind of clothing and BMI. Vitamin D deficiency was more evidence in Tehran (Moradzadeh et al., 2008), having highest prevalence of deficiency in Tehranian men, while the lowest prevalence was reported in Mashhad (north east of Iran) and Boosher (south of Iran) among men and women. Similarly Rahnavard et al., (2010) in a study in 5 major cities reported that the Geographical zone independently predicts vitamin D status that Tehranian had highest prevalence and there was not significant association between age, physical activity and duration of exposure of face and hands to sunlight with circulating blood vitamin D levels. However those who exposed most parts of their body to the sunlight had significantly higher vitamin D level and participants who did not exposed their skin to the sunlight had significantly lower vitamin D status (Rahnavard et al., 2010). Among Iranian mothers the cord serum $25-\mathrm{OH}$ D concentration was very low $(4.94 \pm 9.4 \mathrm{nmol} / \mathrm{l})$ and infants' hypovitaminosis D were undetectable (Basir et al., 2001).

Although vitamin D intake from animal sources in our studied population was very low and $90-95 \%$ of population did intake less than RDA of $10 \mu \mathrm{g} /$ day, but the energy intake in the region was sufficient to provide vitamin D during exposing body skin to sunlight. However, our initial biochemical and clinical study in the studied population and also biochemical analysis across country showed that the vitamin D deficiency is wide spread and even in some regions its prevalence is up to $75 \%$. Comparison of prevalence of vitamin D deficiency in different region reveals that there may be several factors affecting on vitamin D deficiency. These factors are such as (1) air pollutions which is very high in Tehran, where the vitamin D deficiency prevalence is high. (2) Sea food consumption which is rich in vitamin D and is consumed in coastal cities such as Bosher the low prevalence vitamin D deficiency region in Iran (Rahnavard et al., 2010). (3) Clothing habits especially among women which is believed to be an important factor in vitamin D deficiency and sun barrier in some countries 
such as Saudi Arabia (Lips, 2007) is not the case in Iran. Similar rate of vitamin D deficiency was observed among women and men in Iran. The vitamin D deficiency among women in Bosher (south of Iran) who have high covering rate, is the least among other studied cities in Iran (Heshmat et al., 2008). The noticeable point is that the vitamin D deficiency among Iranian populations residing in other countries is prevalent (Holvik et al., 2005).

In our current study the mean fiber consumption was $20 \mathrm{gr}$ a day which is indication of diet rich in vegetable sources and contains higher phytates and lower animal proteins. High phytates and low animal proteins in diets are known as a factor for vitamin deficiency (Reinhold, 1976; Smith, 1990; Finch et al., 1992). Due to drinking black tea in Iranian society, higher amount of florid intake was observed in our studied subjects. Florid may interfere with $\mathrm{Ca}^{2+}$ and vitamin D absorption (Goel et al., 1976).

There were limitations in our study. We did not measure blood vitamin D to compare relation between vitamin D intake and circulating blood vitamin D. We also did not measure the sunlight exposure duration of subjects to estimate the vitamin D deficiency severity among expose and non-expose subjects to sunlight.

In summary different factors affect on vitamin D deficiency including primary low intake of vitamin D, lack of exposure to sunlight, skin pigmentation, altitude of region and genetics characteristics.

Due to life style of Iranian and also Asian countries populations which results in lack of moderate exposure to sunlight, we recommend that, the regular vitamin $\mathrm{D}$ fortification program in national level in order to combat vitamin D deficiency as a public health issue is needed.

\section{Acknowledgments}

The authors would like to express their gratitude to research team of Metabolic Disease Research Center, Qazvin University of Medical Sciences. We also thank all residents of Minodar area who voluntary participated in this study.

\section{References}

Basir, M., Laborie, S., Lapillonne, A., Claris, O., Chappuis, M., \& Salle, B. L. (2001). Vitamin D deficiency in Iranian mothers and their neonates: a pilot study. Acta Paediatr, 90, 577-79. http://dx.doi.org/10.1111/j.1651-2227.2001.tb00802.x

Diet Analysis. (2011). Nutrition 4, Module Version 3.5.2, Iranian modified version, Tehran.

ERC. (2012). Endocrine Research Center, Tehran lipid and glucose study. Shahid Beheshti University of Medical Sciencce. Retrieved September, 2012, from http://www.erc.iran.com/tlgs

Finch, P., Ang, L., \& Colston, K. (1992). Blunted seasonal variation in serum 25-hydroxy vitamin D and increased risk of osteomalacia in vegetarian London Asian. Eur J Clin Nutr, 46, 509-15.

Goel, K. E., Sweet, E., \& Logan, R. (1976). Florid and subclinical rickets among immigrant children in Glasgow. Lancet, 1, 1141-1145. http://dx.doi.org/10.1016/S0140-6736(76)91538-5

Hashemipour, S., Larijani, B., Adibi, H., Javadi, E., Sedaghat, M., Pajouhi, M., ... Booya, F. (2004). Vitamin D deficiency and causative factors in the population of Tehran. BMC Public Health, 4, 38. http://dx.doi.org/10.1186/1471-2458-4-38

Heshmat, R., Mohamad, K., Majdzadeh, S., Forouanzanfar, M., Bahrami, A., Ranjbar, G. H., ... Larijani, B. (2008). Vitamin D deficiency in Iran: A multi-center study among different urban areas. Iranian J Publ Health, 1, 72-78.

Holick, M., \& Chen, T. (2008). Vitamin D deficiency: a worldwide problem with health. Am J Clin Nutr, 87(suppl), 1080S-6S. Retrieved on September 10, 2011, from www.ajcn.org

Holvik, K., Meyer, H., Haug, E., \& Brunvand, L. (2005). Prevalence and predictors of vitamin D deficiency in five immigrant groups living in Oslo, Norway: The Oslo Immigrant Health Study. Eur J Clin Nutr, 59(1), 57-63. http://dx.doi.org/10.1038/sj.ejcn.1602033

Lips, P. (2007). Vitamin D status and nutrition in Europe and Asia. J Steriod Biochem Mol Biol, 103, 620-25. http://dx.doi.org/10.1016/j.jsbmb.2006.12.076

Londhey, V. (2011). Vitamin D deficiency: Indian scenario. JAPI, 59, 695-96.

Mahan, L. K., \& Escott-Stump, S. (2012). Krause's food, nutrition and diet therapy. Philadelphia, W.B. Saunders.

Moradzadeh, K., Larijani, B., Keshtkar, A., Hossein-Nezhad, A., Rajabian, R., et al. (2008). Normative value of vitamin D among Iranian population: A population based study. International journal of Osteoporosis and 
Metabolic Disorders, 1(1), 8-15.

Rahnavard, Z., Eybpoosh, S., Rezaei-Homami, M., Aghaei-meybodi, H., Azemati, B., et al. (2010). Vitamin D deficiency in healthy male population: Results of the Iranian multi-center osteoporosis study. Iranian J Publ Health, 39(3), 45-52.

Reinhold, J. (1976). Rickets in Asian immigrants. Lancet, 2, 1132-1133. http://dx.doi.org/10.1016/S0140-6736(76)91104-1

Satman, I., Ozbey, N., Boztepe, H., Kalaca, S., Genc, S., et al. (2012). Prevalence of vitamin D deficiency and associated factors in Turkey. Endocr Rev, 33, 349. http://edrv.endojournals.org/cgi/conten

Smith, R. (1990). Asian rickets and osteomalacia. Q J Med, 76, 899-901.

Sun, Q., Shi, L., Rimma, E., Giovannucci, E., Hu, F., Manson, J. E., \& Rexrode, K. M. (2011). Vitamin D intake and risk of cardiovasculare disease in US men and women. Am J Clin Nutr, 94(2), 534-542. http://dx.doi.org/10.3945/ajcn.110.008763

Talaei, A., Yadegari, N., Rafee, M., Rezvanfar, M., \& Moini, A. (2012). Prevalence and cut off point of vitamin D deficiency among secondary students of Arak, Iran in 2010. Indian Journal of Endocrinology and Metabolism, 16(5), 786-90. http://www.ijem.in Accessed: Oct. 2012.

Zhu, Z., Zhan, J., Shao, J., Chen, W., Chen, L., Li, W. H., ... Zhao, Z. Y. (2012). Vitamin D Deficiency in China. BMC Public Health, 12, 126. http://dx.doi.org/10.1186/1471-2458-12-126 